\title{
Hexagonal Printed Monopole Antenna with Triple Stop Bands for UWB Applications
}

\author{
MUHAMMAD IRFAN KHATTAK*, MUHAMMAD IRSHAD KHAN*, ZAKA ULLAH*, \\ GULZAR AHMAD*, AND AMAD KHAN**
}

RECEIVED ON 29.01.2018 ACCEPTED ON 25.05.2018

\begin{abstract}
Inherently UWB (Ultra Wideband) communication systems comes with interference problem with some of the existing narrowband communication systems. These bands are stopped with the help of band-stop filter in order to reduce electromagnetic interference. However, the complexity and limitations are increased due to these filters, hence this solution is turned down in those applications where design complications and complexity is of concern. Introducing various slots of specific shapes and exact dimensions however, have solved this issue for the researchers around the world. This paper presents a hexagonal PMA (Printed Monopole Antenna) with triple stop bands. The antenna is used for UWB application. The antenna is stopped the WiMAX (Worldwide Interoperability for Microwave Access), WLAN (Wireless Local Area Network) and ITU (International Telecommunication Union) bands. The

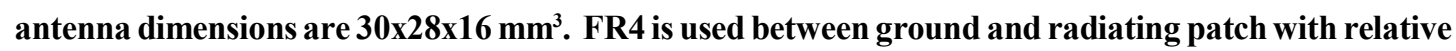
permittivity of 4.4. The VSWR (Voltage Standing Wave Ratio) is less than 2 between 3-11 GHz except WiMAX (3.1-3.7 GHz), WLAN (5.1-5.8 GHz) and the ITU frequency band (7.95-8.4 GHz). The antenna is design in CST software.
\end{abstract}

Key Words: Computer Simulation Technology, Voltage Standard Wave Ratio,Worldwide Interoperability for Microwave Access, Wireless Local Area Network, Ultra Wideband, International Telecommunication Union.

\section{INTRODUCTION}

$\mathrm{U}$

WB communication is under consideration in last decade due to wide bandwidth, short range, simple implementation and high data rate [1]. FCC (Federal Communication Commission) [2] allocated the frequency spectrum from 3.1-10.6 GHz. UWB has very larger bandwidth so interference occurred with existing narrow bands. The narrow bands are WLAN,
WiMAX and ITU. These bands are stopped with the help of band-stop filter in order to reduce electromagnetic interference. However, the complexity and limitations are increased due to these filters. Therefore, the PMA with notched characteristics is required to reduce the interference, which is very simple, low profile, compact in size, easy in installation and fabrication.

Auhtors E-Mail: (m.i.Khattak@uetpeshawar.edu.pk, gulzar@uetpeshawar.edu.pk, irshadnawab@outlook.com,zakabarki@gmail.com, amadullah@uetpeshawar.edu.pk)

* Department of Electrical Engineering, University of Engineering \& Technology, Peshawar, Pakistan

** Department of Chemical Engineering, University of Engineering \& Technology, Peshawar, Pakistan.

This is an open access article published by Mehran University Research Journal of Engineering and Technology, Jamshoro under the CC by 4.0 International License. 
The stop band antenna with size of $30 \times 30 \times 1.6 \mathrm{~mm}^{3}$ is propounded, the dual band are stopped with the help of slots in radiator and ground [3]. The PMA with stop band characteristic is presented, the size of the antenna is $48.7 \times 42 \mathrm{~mm}$ [4]. Liu et. al. [5] designed notched band antenna with large size of 40x40mm. The dual stop band circular design with size of $35.5 \times 30 \times 1.6 \mathrm{~mm}$ is propounded, the antenna is printed on FR4 substrate [6]. The U shaped antenna with dual notched band is proposed, the bands is stopped with CSRR (Complementary Split Ring Resonator) and $\mathrm{T}$ shaped slot and the size of antenna is $24.6 \times 38.1 \mathrm{~mm}^{2}$ [7]. The triple notched band antenna with dimension of $24 \times 34.6 \mathrm{~mm}$ is designed, the height of substrate is $.8 \mathrm{~mm}$ [8]. The circular antenna is presented to stop triple bands by using square short resonator, the size of the antenna is $40 \times 20 \times 0.508 \mathrm{~mm}^{3}$ [9]. The PMA with size of $60 \times 60 \times 1.6 \mathrm{~mm}^{3}$ is designed, the author used various shaped slot and $\mathrm{F}$ shaped stub to stop various bands [10]. The PMA is proposed with the rejection of two bands with the help of two slots, the dimension of the design is $31 \times 31 \times 1.15 \mathrm{~mm}^{3}$ [11]. The single stop band PMA with circular slot is propounded, the size of the antenna is $50 \times 50 \times 0.5 \mathrm{~mm}^{3}[12]$.

Recently various stop band printed antennas are reported where the band are stopped due to SRR, CSRR, open loop resonator, parasitic strips and embedded $\mathrm{T}$ shaped stub [13-16]. The interference of existing narrow bands are also reduce due to introducing different shapes of slot in radiator patch, ground and feed line such as Tshaped, E-shaped slot, symmetrical elliptical slots, fractal shaped slot, C-shaped slots, inverted C-shaped slots, semi-elliptical slot, U-shaped slot, L-shaped slot, circular slot and rectangular slot [17-24]. The detailed comparison is given in the Table 1.

In this paper, simple hexagonal PMA is presented which is designed on FR4 dielectric substrate. The size of the antenna is $30 \times 28 \times 0.6 \mathrm{~mm}$. The antenna is simulated in CST software. The slots are introduced to stop the bands of WiMAX (3.1-3.7 GHz), WLAN (5.1-5.8 GHz) and the ITU frequency band $(7.95-8.4 \mathrm{GHz})$.

\section{ANTENNA DESIGN}

Proposed Hexagonal shaped PMA with stop band is presented. The size of the antenna is $30 \times 28 \times 1.6 \mathrm{~mm}^{3}$ The proposed antenna has hexagonal shaped radiating patch with each side of $10 \mathrm{~mm}$. The hexagonal PMA have three slots such as rectangular slot, $\mathrm{U}$ shaped slot and inverting $\mathrm{U}$ shaped slot in feed line. The rectangular slot has 12.5 $\mathrm{mm}$ length and $0.3 \mathrm{~mm}$ width which filtered the band of WiMAX. The size of the U shaped slot is $18.7 \times 0.5 \mathrm{~mm}$, stopped the band of WLAN. The dimensions of the inverting $\mathrm{U}$ shaped slot is $12.3 \times 0.6 \mathrm{~mm}$, stopped the band of ITU $8 \mathrm{GHz}$. The feed line is $3 \mathrm{~mm}$ wide and $8 \mathrm{~mm}$ long. The height of the ground is $8 \mathrm{~mm}$ and width is $28 \mathrm{~mm}$ and various other parameter is discussed in Table 2 . The antenna is fed with $50 \&$ ! transmission line. The complete antenna design is depicted in Fig. 1(a-b) and its $\mathrm{S}_{11}$ is shown in Fig. 2. The VSWR of proposed antenna is also illustration in Fig. 3. The length of slots can be calculated from bellow postulate [3].

$$
L_{s 1}=\frac{c}{4 f_{n} \sqrt{\left(\frac{s_{r}+1}{2}\right)}}
$$

TABLE 1. COMPARISON BETWEEN PROPOSED ANTENNA AND AVAILABLE IN THE LITERATURE

\begin{tabular}{|c|c|c|c|}
\hline No. & Author & Size $\left(\mathrm{mm}^{3}\right)$ & Stop Bands \\
\hline 1. & Sarkar et. al. [25] & $35 \times 35 \times 1.6$ & 3 \\
\hline 2. & Shi et. al. [6] & $35.5 \times 30 \times 1.6$ & 2 \\
\hline 3. & Gao et. al. [7] & $24.6 \times 38.1 \times 1.5$ & 3 \\
\hline 4. & Sarkar et. al. [8] & $24 \times 34.6 \times 0.8$ & 3 \\
\hline 5. & Proposed Hexagonal PMA & $32 \times 30 \times 1.6$ & 2 \\
\hline
\end{tabular}

Mehran University Research Journal of Engineering \& Technology, Volume 38, No. 2, April, 2019 [p-ISSN: 0254-7821, e-ISSN: 2413-7219] 


$$
L_{s 2}=\frac{c}{2 f_{n} \sqrt{\left(\frac{s_{r}+1}{2}\right)}}
$$

TABLE 2. PARAMETER OF PROPOSED HEXAGONAL PMA

\begin{tabular}{|c|c|c|c|}
\hline Parameters & $\begin{array}{c}\text { Value } \\
(\mathrm{mm})\end{array}$ & Parameters & $\begin{array}{c}\text { Value } \\
(\mathrm{mm})\end{array}$ \\
\hline $\mathrm{L}$ & 30 & $\mathrm{~L} 3$ & 1 \\
\hline $\mathrm{W}$ & 28 & $\mathrm{H} 6$ & 8 \\
\hline $\mathrm{Lg}_{1}$ & 3.5 & $\mathrm{~L} 1$ & 1 \\
\hline $\mathrm{H}_{2}$ & 10 & $\mathrm{~L} 4$ & 12.5 \\
\hline $\mathrm{Lg}_{2}$ & 3.5 & $\mathrm{H} 1$ & 6 \\
\hline $\mathrm{H}_{4}$ & 6 & $\mathrm{H} 3$ & 5.5 \\
\hline $\mathrm{W}_{\mathrm{g}}$ & 3.3 & $\mathrm{Wf}$ & 3 \\
\hline $\mathrm{L}_{2}$ & 7 & $\mathrm{H} 5$ & 5.5 \\
\hline
\end{tabular}

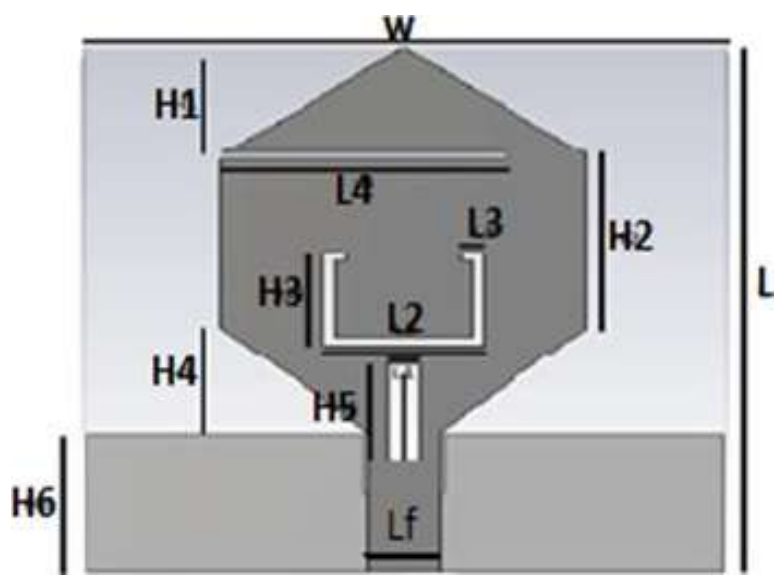

(a) TOP VIEW

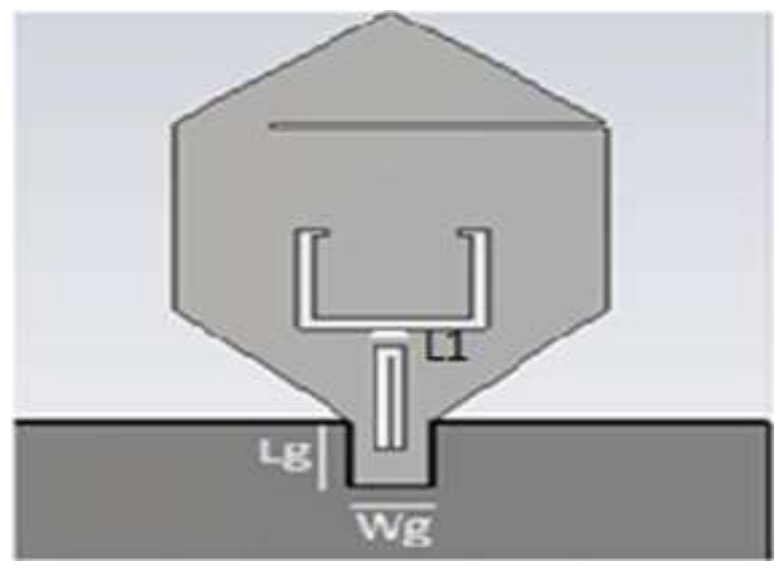

(b) BOTTOM VIEW

FIG. 1. PROPOSED PMA
$L_{s 1}$ denotes the length of rectangular slot, $L_{s 2}$ denotes the length of $\mathrm{U}$ shaped slot, $f_{n}$ is notch frequency and $\varepsilon_{r}$ is relative permittivity. The rectangular slot is $\lambda / 4$ at stop band frequencies and remain two slots are $\lambda / 2$ at stop band frequencies.

\section{RESULTS AND DISUCUSION}

The VSWR is less than 2 between $3-11 \mathrm{GHz}$ except WiMAX (3.1-3.7GHz), WLAN (5.1-5.8GHz) and the ITU frequency band $(7.95-8.4 \mathrm{GHz})$. The impedance bandwidth of proposed PMA is $8 \mathrm{GHz}$ which can be justified from Fig. 2. The antenna Gain is higher at resonating frequency as compared to notched frequencies which is shown in Fig. 4. The E and H-plane radiation pattern at various frequencies are depicted in Fig. 5(a-c). In E-plane the pattern is same to dipole antenna and in H-plane the pattern is nearly omni-directional.

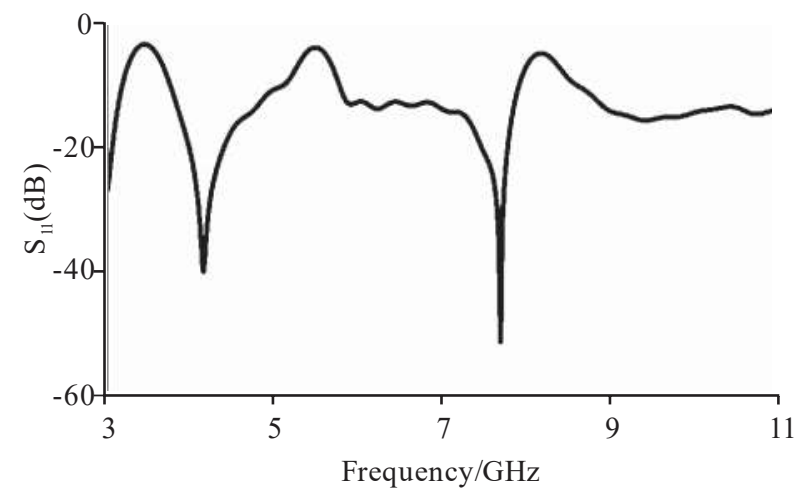

FIG. 2. SIMULATED $S_{I I}$ (DB) OF HEXAGONAL PMA

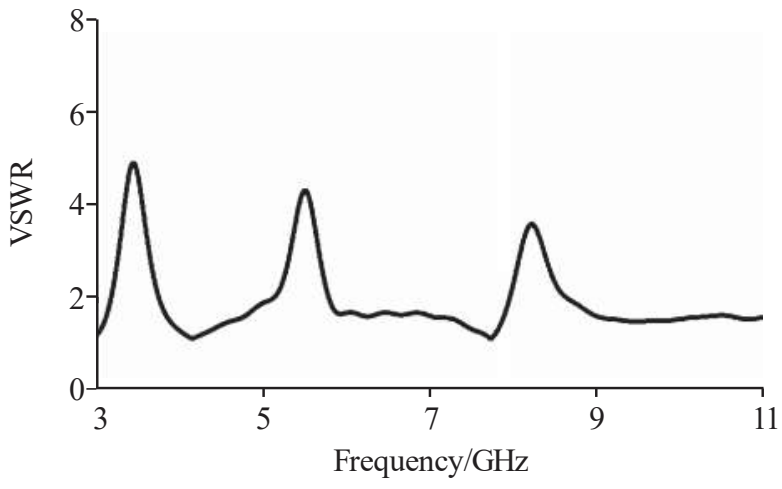

FIG. 3. SIMULATED VSWR OF PROPOSED PMA 
The vector current distribution at different notched frequencies are given in Fig. 6(a-c). The current is flowing around rectangular slot but in opposite

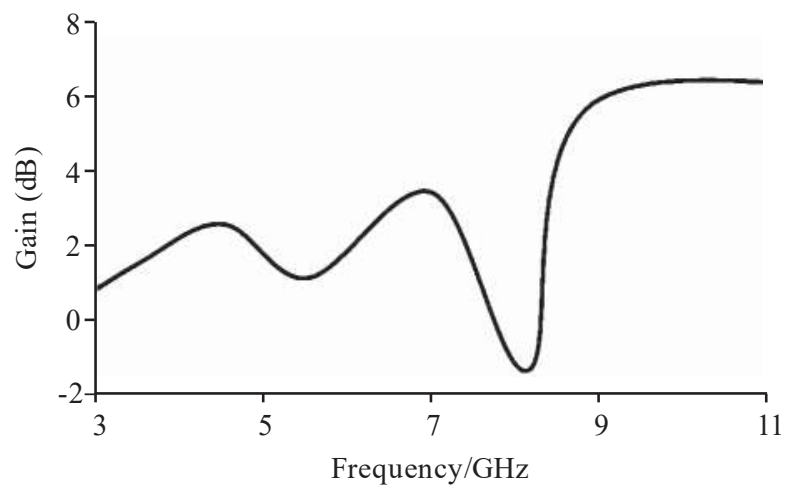

FIG. 4. SIMULATED GAIN OF TRIPLE STOP BAND PMA direction which cancelled effect of each other and stop band occurred at $3.5 \mathrm{GHz}$ due to this phenomenon. Similarly, the 5.5 and $8.1 \mathrm{GHz}$ band are stop due to $\mathrm{U}$ shaped and inverted $U$ shaped slot which is clearly illustrated in Fig. 6.

The photographical image of presented design is depicted in Fig. 7(a-b). The design is tested through Agilent Technologies Network Analyzer N5242A. The measured and simulated $\mathrm{S}_{11}$ and VSWR is shown in Figs. 8-9 respectively. The slight shift occurred due to SMA connecter and Fabrication error.

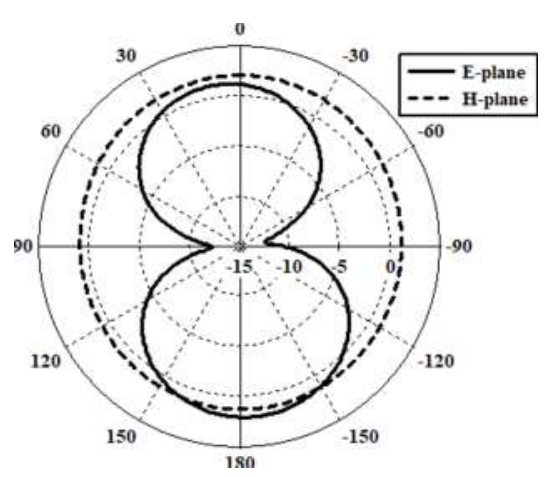

(a) $3.1 \mathrm{GHZ}$

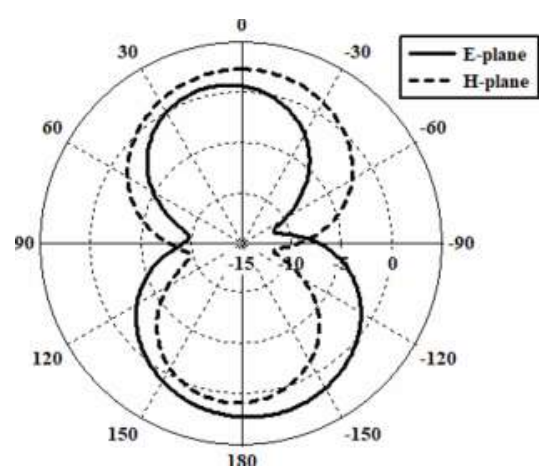

(b) $4.1 G H Z$

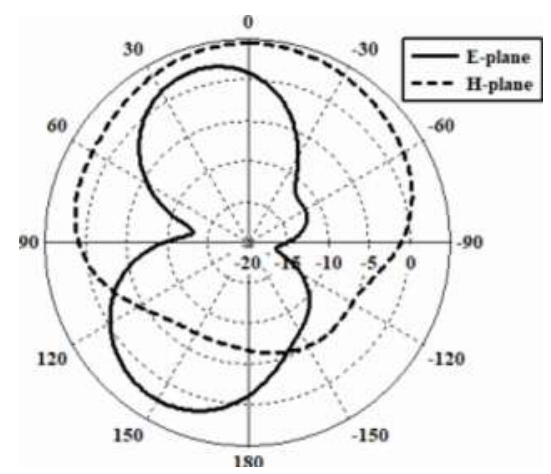

(c) $7.7 \mathrm{GHZ}$

FIG. 5. SIMULATED RADIATION PATTERN OF TRIPLE STOP BAND PMA

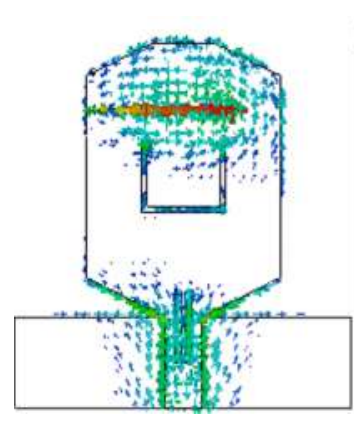

(a) $3.5 G H Z$
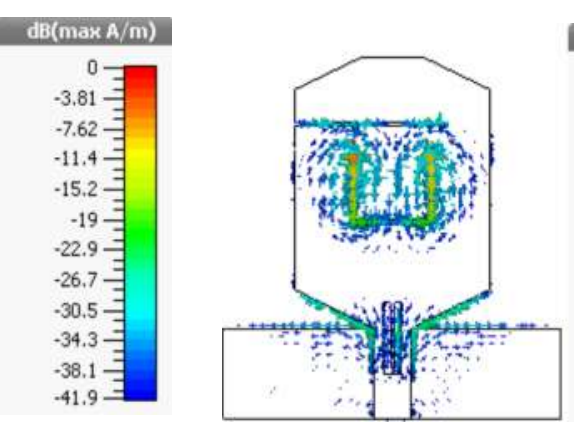

(b) $5.5 \mathrm{GHZ}$
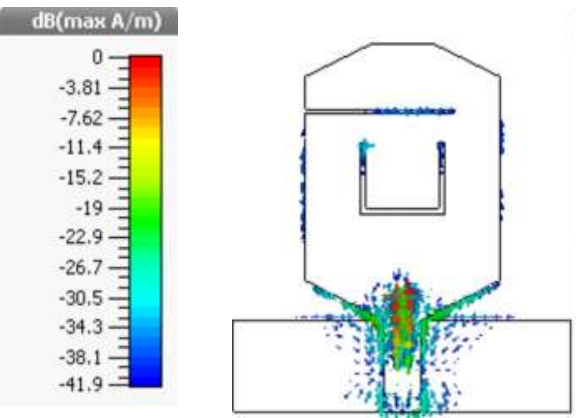

(c) $8.1 \mathrm{GHZ}$

FIG. 6. SURFACE CURRENT DISTRIBUTION OF TRIPLE STOP BAND PMA 


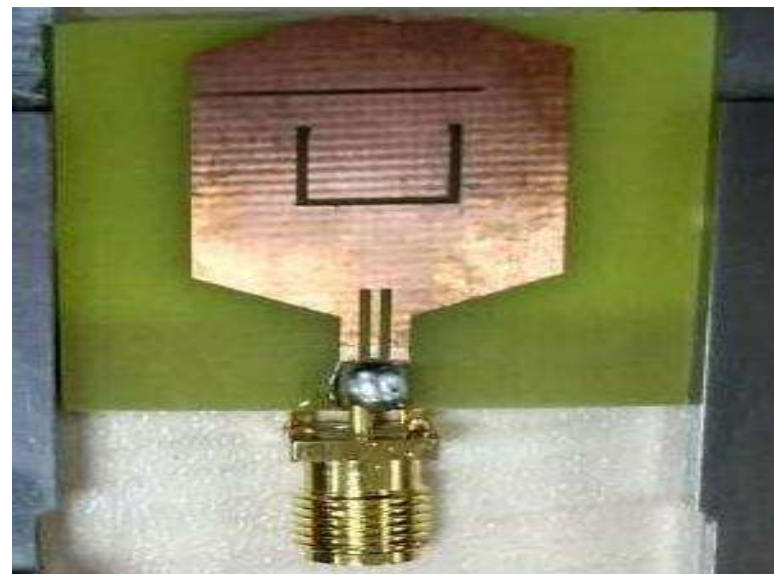

(a) TOP VIEW

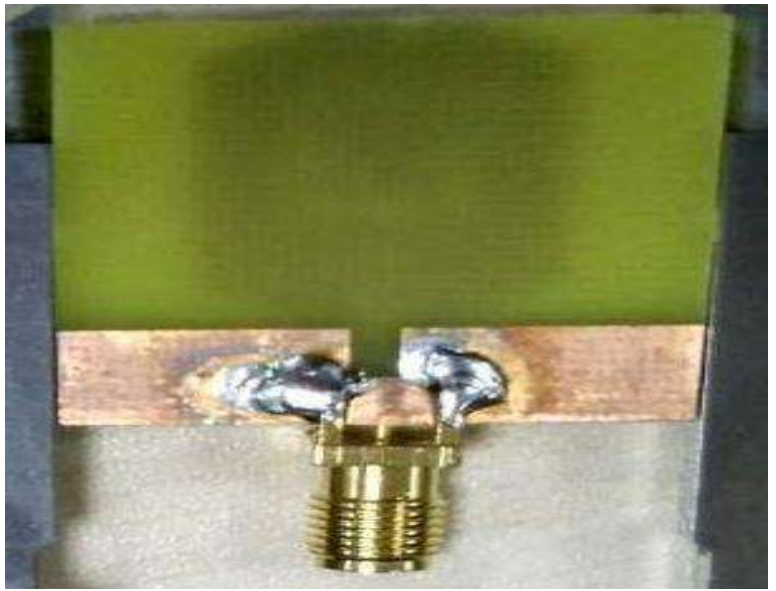

(b) BOTTOM VIEW

FIG. 7. PHOTOGRAPHIC IMAGE OF TRIPLE STOP BAND PMA

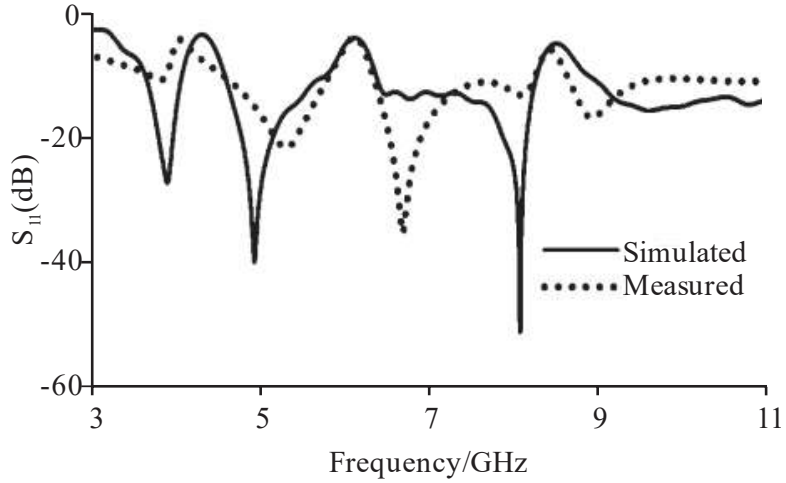

FIG. 8. SIMULATED AND MEASURED $S_{I I}(D B)$ OF

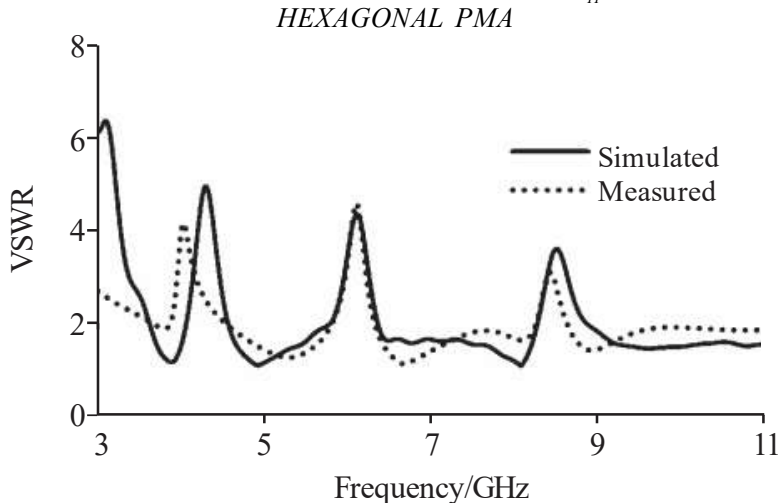

FIG. 9. SIMULATED AND MEASURED VSWR OF TRIPLE STOP BAND PMA

\section{CONCLUSION}

UWB communication systems have interference problem with existing narrowband communication systems. These bands are stopped with the help of band-stop filter in order to reduce electromagnetic interference. However, the complexity and limitations are increased due to these filters. The aim of the research is to design compact size PMA with band stop characteristics to reduce interference with existing narrow bands. Therefore, the PMA with notched characteristics is required to reduce the interference, which is very simple, low profile, compact in size, easy in installation and fabrication. The antenna is resonating from 3-11 GHz except stop bands. The slots are introduced to stop the bands of WiMAX, WLAN and the ITU frequency band.

\section{ACKNOELEDGEMENT}

Authors acknowledge the support given by the Microwave and Antenna Research Group, Department of Electrical Engineering, University of Engineering \& Technology, Kohat Campus, Peshawar, Pakistan. This support was in the form of access to the recent good quality research papers and also in the form of valuable comments whenever required regarding the concept of the research field.

\section{REFERENCES}

[1] Sharma, M.M., Deegwal, J.K., Kumar, A., and Govil, M.C., "Compact Planar Monopole UWB Antenna with Quadruple Band-Notched Characteristics", Progress in Electromagnetics Research, Volume 47, pp. 29-36, 2014.

[2] FCC (Federal Communications Commission), "Commission's Rule Regarding Ultra-Wideband Transmission", First Report and Order, Revision of Part-15, 2002 . 
[3] Zheng. Z.A., and Chu, Q.X., "Compact CPW-Fed UWB Antenna with Dual Band-Notched Characteristics", Progress in Electromagnetics Research Letters Volume 11, pp. 83-91, 2009.

[4] Yin. X.C., Ruan, C.L., Mo, S.G., Ding, C.Y., and Chu, J.H., "A Compact Ultra-Wideband Microstrip Antenna with Multiple Notches", Progress in Electromagnetics Research, Volume 84, pp. 321-332, 2008.

[5] Liu. H.W., Ku, C.H., and Yang, C.F., "Novel CPW-Fed Planar Monopole Antenna for WiMAX/WLAN Applications", IEEE Antennas and Wireless Propagation Letters, Volume 9, pp. 240-243, 2010.

[6] Shi, R., Xu, X., Dong, J., and Luo, Q. "Design and Analysis of a Novel Dual Band-Notched UWB Antenna", International Journal of Antennas and Propagation, 2014.

Gao, G., He, L., Hu, B., and Cong, X., "Novel Dual Band Notched UWB Antenna with T Shaped Slot and CSRR Structure", Microwave and Optical Technology Letters, Volume 57, pp. 1584-1590, 2015.

[8] Sarkar, M., Dwari, S., and Daniel, A., "Printed Monopole Antenna for Ultra-Wideband Application with Tunable Triple Band-Notched Characteristics", Wireless Personal Communications, Volume 84, pp. 2943-2954, 2015.

[9] Wang, Z., and Zhang, C., "A Planar UWB Antenna with Triple-Notched Bands", Progress in Electromagnetics Research Letters, Volume 52, pp. 99-104, 2015.

[10] Rahimi, M., Sadeghzadeh, R., Zarrabi, F.B., and Mansouri, Z., "Band-Notched UWB Monopole Antenna Design with Novel Feed for Taper Rectangular Radiating Patch", Progress in Electromagnetics Research-C, Volume 47, pp. 147-155, 2014.

[11] Chaabane, A., Djahli, F., and Redadaa, S., "A Dual-BandNotched Antenna for UWB Communication Systems Using Two Different Shaped Slots", Arabian Journal for Science \& Engineering, Volume 39, No. 8, pp. 6215-6223, 2014.

[12] Kalteh, A.A., Fallahi, R., and Roozbahani, M.G., "Design of a Band-Notched Microstrip Circular Slot Antenna for UWB Communication", Progress in Electromagnetics Research-C, Volume 12, pp. 113-123, 2010.

[13] Peng, L., and Ruan, C.L., "Design and Time-Domain Analysis of Compact Multi-Band-Notched UWB Antennas with EBG Structures", Progress in Electromagnetics Research-B, Volume 47, pp. 339-357, 2013.

[14] Zhang, Y., Hong, W., Yu, C., Kuai, Z.Q., Don, Y.D., and Zhou, J.Y., "Planar Ultra Wideband Antenna with Multiple Notched Bands Based on Etched Slots on the Patch and/or Split Ring Resonators on the Feed Line", IEEE Transactions on Antennas and Propagations, Volume 56, pp. 3063-3068, 2008.
[15] Li, T., Zhai, H., Li, L., Liang, C., and Han, Y., "Compact UWB Antenna with Tunable Band Notched Characteristic Based on Microstrip Open-Loop Resonator", IEEE Transactions on Antennas \& Wireless Propagation Letters, Volume 11, pp. 1584-1587, 2012

[16] Jiang, W., and Che, W., "A Novel UWB Antenna with Dual Notched Bands for WiMAX and WLAN Applications", IEEE Transactions Antennas \& Wireless Propagation Letters, Volume 11, pp. 293-296, 2012.

[17] Gopikrishna, M., Krishna, D.D., and Aanandan, C.K., "Band-Notched Semi-Elliptic Slot Antenna for UWB Systems", Proceedings of $38^{\text {th }}$ European Microwave Conference, pp. 889-892, Amsterdam, 2008.

[18] Zhu, X.F., and Su, D.L., "Symmetric E-Shaped Slot for UWB Antenna with Band-Notched Characteristics", Microwave and Optical Technology Letters, Volume 52, pp. 1594-1597, 2010.

[19] Su, S.W., Wong, K.L., and Chang, F.S., "Compact Printed Band-Notched Ultra-Wideband Slot Antenna", IEEE International Symposium on Antennas and Propagation Society, Volume 2B, pp. 572-575, 2005.

[20] Sharma. M.M., Kumar, A., Ranga, Y., and Bhatnagar, D., "An Ultra-Wideband Antenna with Axis Symmetrical Elliptical Slots for Tunable Band-Notched Characteristics", IEEE Asia Pacific Microwave Conference, pp. 725-728, 2011.

[21] Zaker, R., Ghobadi, C., and Nourinia, J., "Bandwidth Enhancement of Novel Compact Single and Dual BandNotched Printed Monopole Antenna with a Pair of LShaped Slots", IEEE Transactions on Antennas and Propagation, Volume 57, pp. 3978-3983, 2009.

[22] Liu, W.J., Cheng, C.H., and Zhu, H.B., "Compact Frequency Notched Ultra-Wideband Fractal Printed Slot Antenna”, IEEE Microwave Wireless Component Letters, Volume 16, No. 4, pp. 224-226, April, 2006.

[23] Fallahi, R., and Roozbahani, M.G., "Design of a BandNotched Microstrip Circular Slot Antenna for UWB Communication", Progress in Electromagnetics Research-C, Volume 12, pp. 113-123, 2010.

[24] Khan, M.I., Rahman, S., Khan, M.K., and Saleem, M., "A Dual Notched Band Printed Monopole Antenna for Ultra Wide Band Applications", Progress in Electromagnetics Research, pp. 4390-4393, PIERS Shanghai, 2016

[25] Sarkar, D., Srivastava, K.V., and Saurav, K., "A Compact Microstrip-Fed Triple Band-Notched UWB Monopole Antenna", IEEE Antennas and Wireless Propagation Letters, 2014. 